\title{
Soroepidemiologia da leptospirose e brucelose bovina em propriedades rurais de agricultura familiar do agreste paraibano, Nordeste do Brasil
}

\author{
Seroepidemiology of bovine leptospirosis and brucellosis in \\ family farm rural properties in the State of Paraíba, northeastern Brazil \\ Robério Macedo de Oliveira', Maria Luana Cristiny Rodrigues Silva', Meire Maria Silva Macêdo', \\ Severino Silvano dos Santos Higino', Lilia Marcia Paulin², Clebert José Alves', \\ Maria das Graças Xavier de Carvalho', Sérgio Santos de Azevedo ${ }^{1 *}$
}

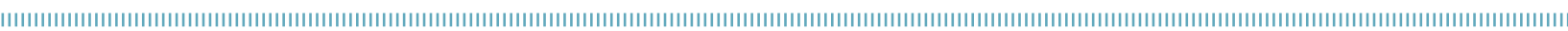

RESUMO: Este trabalho teve como objetivo determinar a frequência de rebanhos positivos e de animais soropositivos para leptospirose e brucelose bovina em propriedades rurais de agricultura familiar da mesorregião do Agreste, estado da Paraíba, bem como identificar fatores de risco. Foram colhidas amostras de sangue de 771 animais procedentes de 130 rebanhos em cinco municípios. Para o diagnóstico sorológico da leptospirose, utilizou-se o teste de soroaglutinação microscópica (SAM), com 24 sorovares de Leptospira spp. como antígenos, e para brucelose, o teste do antígeno acidificado tamponado (AAT) como prova de triagem e o teste do 2-mercaptoetanol (2-ME) como prova confirmatória. Para leptospirose, a frequência de propriedades positivas e animais soropositivos foi de 18,4 e 3,6\%, respectivamente; para brucelose, 7,7\% das propriedades e 1,9\% dos animais foram positivos. O sorovar de Leptospira spp. mais frequente foi o Hardjo. A compra de bovinos foi identificada como fator de risco para brucelose bovina (odds ratio $=5,25 ; \mathrm{p}=0,044$ ). Sugere-se a necessidade de adoção e/ou intensificaçãa de medicas de prevenção e controle com o objetivo de evitar perdas econômicas e transmissão dos agentes aos seres humanos, bem como a compra de animais precedida do conhecimento da sua condição sanitária.

PALAVRAS-CHAVE: Leptospira spp.; Brucella abortus; propriedades de agricultura familiar; sorologia; fatores de risco.

\begin{abstract}
The aim of this investigation was to determine the frequency of positive herds and seropositive animals to bovine leptospirosis and brucellosis in family farm rural properties from the mesoregion of the State of Paraíba, as well as to identify risk factors. Blood samples were collected from 771 animals from 130 herds in five municipalities. For the serological diagnosis of leptospirosis, the microscopic agglutination test (MAT) using 24 Leptospira spp. serovars as antigens was carried out, and for brucellosis the Rose-Bengal Test (RBT) was used as screening test and the 2-mercaptoethanol test (2-ME) to confirm. For leptospirosis, the frequency of positive herds and seropositive animals was 18.4 and $3.6 \%$, respectively; for brucellosis, $7.7 \%$ of the herds and $1.9 \%$ of the animals were positive. The most frequent Leptospira spp. serovar was Hardjo. Bovine purchase was identified as a risk factor to bovine brucellosis (odds ratio = 5.25; $\mathrm{p}=0.044)$. The need for adoption and/or intensification of control and prevention measures was suggested in order to avoid economic losses and the transmission of the agents to humans, as well as the purchase of animals with known sanitary conditions.
\end{abstract}

KEYWORDS: Leptospira spp.; Brucella abortus; family farm properties; serology; risk factors. 


\section{INTRODUÇÃO}

A atividade agropecuária brasileira tem assumido, nos últimos anos, importante participação na economia, sendo um componente relevante do Produto Interno Bruto (PIB) e da geração de riqueza do país. A pecuária bovina ganhou relevância, tanto no cenário interno quanto no externo, e atualmente o Brasil possui um dos principais rebanhos comerciais do mundo (IвGE, 2006), assim como é um dos principais países produtores de leite, apresentando uma taxa de crescimento anual de $4 \%$, superior à dos países que ocupam os primeiros lugares. Em análise retrospectiva, a produção brasileira de leite nos últimos 25 anos aumentou $150 \%$, passando de 8 bilhóes de litros no ano de 1975 para 19,8 bilhóes no ano 2000, ultrapassando 26 bilhóes em 2007 (Embrapa Gado De Leite, 2012).

No Censo Agropecuário de 2006 foram identificados 4.367.902 estabelecimentos de agricultura familiar no Brasil, responsáveis por $58 \%$ de todo o leite produzido no país. No estado da Paraíba, 69\% do leite foi produzido em estabelecimentos de agricultura familiar (IBGE, 2006). Neste contexto, o conhecimento da frequência de ocorrência de agentes infecciosos, tais como brucelose e leptospirose, que causam diminuição da produção de leite, torna-se indispensável. Ambas as doenças estâo incluídas na lista de doenças da Organização Mundial de Saúde Animal (World Organization for Animal Health [OIE]), ou seja, são doenças transmissíveis de importância socioeconômica e/ou de saúde pública e que podem ter impacto significativo no comércio internacional de animais e de seus subprodutos (OIE, 2011).

A brucelose bovina é uma doença bacteriana de evolução crônica e caráter granulomatoso difuso, caracterizada pela infecção de células do sistema mononuclear fagocitário. É causada por uma bactéria intracelular facultativa integrante do gênero Brucella, e apresentando-se em todo o mundo como problema sanitário e econômico (Paulin; Ferreira Neto, 2003). O principal agente etiológico é a Brucella abortus, cujo biotipo 1 é o mais frequente (Асна; SZYFres, 2001). As perdas diretas provocadas pela brucelose bovina são decorrentes de abortamentos, baixos índices reprodutivos, aumento do intervalo entre partos, diminuiçáo da produção de carne e leite, morte de bezerros e interrupção de linhagens genéticas. Estimativas mostram que a infecção é responsável pela diminuição de 20 a $25 \%$ da produção de leite, 10 a $15 \%$ da produção de carne, $15 \%$ de perda de bezerros em decorrência de abortamentos, aumento de 30\% da taxa de reposição de animais e aumento do intervalo entre partos de 11,5 para 20 meses. Mostram ainda que, a cada cinco vacas infectadas, uma aborta ou torna-se permanentemente estéril (ACHA; SZYFrEs, 2001).

A leptospirose é uma zoonose bacteriana causada por espiroquetas do gênero Leptospira. Com vasta distribuição geográfica, é evidenciada em todo o mundo e particularmente prevalente em países de clima tropical e subtropical, principalmente nos períodos de altos índices pluviométricos (Acha; Szyfres, 2001) devido à elevada sobrevivência da bactéria em ambientes úmidos, o que aumenta o risco de exposição e contaminação de animais suscetíveis e seres humanos. As perdas econômicas causadas pela leptospirose estâo direta ou indiretamente ligadas às falhas reprodutivas, como infertilidade e abortamento, bem como à queda da produção de carne e leite, além de custos com despesas de assistência veterinária, vacinas e testes de laboratório (FAINE et al., 1999).

Considerando a importância da brucelose e da leptospirose bovina nos aspectos de saúde pública e de perdas econômicas para a produção de bovinos, o objetivo do presente trabalho foi determinar a frequência de rebanhos positivos e de animais soropositivos para ambas as infecçôes, bem como identificar fatores de risco em propriedades rurais de agricultura familiar do agreste do estado da Paraíba.

\section{MATERIAL E MÉTODOS}

Foram utilizados 771 bovinos (523 fêmeas e 248 machos) procedentes de 130 propriedades rurais de agricultura familiar em cinco municípios da mesorregião do agreste paraibano: Araruna (32 propriedades e 183 animais), Belém (43 propriedades e 297 animais), Cacimba de Dentro (35 propriedades e 211 animais), Areial (11 propriedades e 59 animais) e Massaranduba (9 propriedades e 21 animais) (Fig. 1). Não foram adotados critérios probabilísticos para a escolha das propriedades e dos animais, sendo esta baseada no consentimento dos proprietários.

O trabalho de campo foi conduzido de julho a agosto de 2011, e incluiu a colheita de sangue e aplicação de questionário epidemiológico. As amostras de sangue foram colhidas de machos e fêmeas com idade igual ou superior a oito meses, em volumes de $10 \mathrm{~mL}$, pela punção da veia jugular com agulha descartável e tubo com vácuo (sem anticoagulante) com capacidade de $15 \mathrm{~mL}$. Após dessoramento, o soro foi transferido para microtubos e congelado. $\mathrm{O}$ transporte das amostras para o laboratório foi feito em caixas isotérmicas.

O diagnóstico sorológico da leptospirose foi realizado com a técnica de Soroaglutinação Microscópica (SAM), de acordo com Galton et al. (1965) e Cole et al. (1973), utilizando uma coleção de antígenos vivos que incluiu os sorovares Castellonis, Javanica, Tarassovi, Whitcombi, Australis, Autumnalis, Bataviae, Bratislava, Canicola, Copenhageni, Grippotyphosa, Hardjo, Hebdomadis, Pomona, Icterohaemorrhagiae, Sentot, Wolffi, Pyrogenes, Butembo, Cynopteri, Panama, Shermani, Andamana e Patoc. Os soros foram triados na diluição de 1:100, e aqueles 


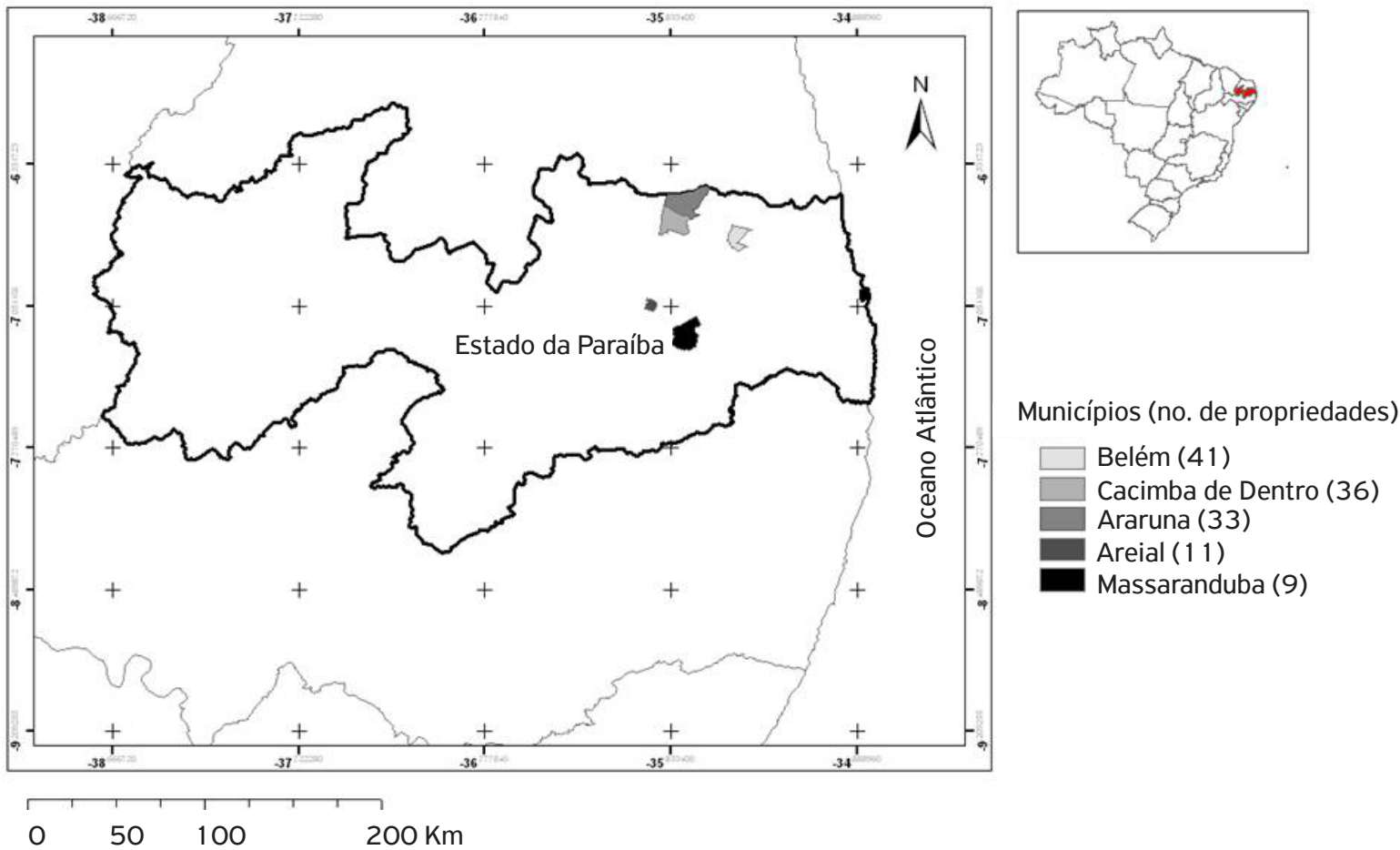

Figura 1. Estado da Paraíba demonstrando os municípios e respectivos números de propriedades rurais utilizadas na mesorregião do agreste paraibano.

que apresentaram 50\% ou mais de aglutinação foram titulados pelo exame de uma série de diluiçôes geométricas de razão dois. O título do soro foi a recíproca da maior diluição que apresentou resultado positivo. Os antígenos eram examinados ao microscópio de campo escuro, previamente aos testes, a fim de verificar a mobilidade e a presença de autoaglutinação ou de contaminantes.

Para o diagnóstico sorológico da brucelose bovina, o teste do Antígeno Acidificado Tamponado (AAT) foi utilizado como prova de triagem, e os soros que reagiram positivamente foram submetidos à prova confirmatória do 2-mercaptoetanol (2-ME) (Brasil, 2006). Paralelamente ao teste do 2-ME, foi realizado o teste de Soroaglutinação Lenta em Tubos (SALT).

Uma propriedade foi considerada positiva quando apresentou pelo menos um animal soropositivo. Para a leptospirose, dentro da propriedade, o sorovar mais frequente foi aquele que apresentou o maior número de animais soropositivos. Para a análise de fatores de risco, foram formados dois grupos de propriedades - positivas e negativas - que, quando comparadas entre si quanto às variáveis pesquisadas no questionário epidemiológico, permitiu medir a força da associação dessas variáveis com a presença das doenças. As variáveis analisadas foram: tipo de criação (confinado, semiconfinado, extensivo), tipo de exploração (corte, leite e misto), número de vacas em lactação, produção diária de leite e tamanho do rebanho (mediana como ponto de corte), presença de outros animais na propriedade (caprino/ovinos, equídeos, suínos, aves, cães e gatos), ocorrência de abortamento, compra de bovinos com finalidade de reprodução, aluguel de pastos, compartilhamento de pastos, presença de áreas alagadiças, posse de piquetes de parição e assistência veterinária.

A análise de fatores de risco foi efetuada em duas etapas: análise univariada e análise multivariada. $\mathrm{Na}$ análise univariada, cada variável independente foi cruzada com a variável dependente (condição sanitária da propriedade). Aquelas que apresentaram valor $\mathrm{p} \leq 0,2$ pelo teste de qui-quadrado (ZAE,1999) foram selecionadas e usadas na análise multivariada, utilizando a regressão logística múltipla (Hosmer; Lemeshow, 2000). O nível de significância adotado na análise múltipla foi de $5 \%$, e todas as análises foram realizadas com o programa SPSS 20.0 for Windows.

\section{RESULTADOS}

Das 130 propriedades investigadas, 24 (18,4\%) apresentaram pelo menos um animal reagente na SAM para qualquer um dos 24 sorovares de Leptospira spp. empregados (Tabela 1). O sorovar Hardjo foi o mais frequente, com $29,16 \%$ de propriedades positivas, seguido pelos sorovares Patoc, Pomona e 
Australis, com 25, 12,5 e 12,5\% de propriedades positivas, respectivamente (Tabela 2). Dos 771 animais investigados, $28(3,6 \%)$ foram soropositivos (Tabela 1). Dentre as fêmeas e machos, $17(3,3 \%)$ e $11(4,4 \%)$ animais foram soropositivos, respectivamente, sem, contudo, haver diferença estatística $(\mathrm{p}=0,411)$. O sorovar mais frequente nos animais também foi o Hardjo, com 35,7\% das reaçóes, seguido pelos sorovares Patoc, Pomona e Australis, com 25, 10,7 e $10,7 \%$ das reaçóes, respectivamente (Tabela 2). Também foram observadas reaçôes para os sorovares Sentot, Shermani e Copenhageni.

Para brucelose, 10 propriedades $(7,7 \%)$ apresentaram animais soropositivos (Tabela 3). Dos 771 animais, 15 $(1,9 \%)$ foram soropositivos nos testes de triagem e confirmatório. Nenhum animal apresentou resultado inconclusivo. O município de Araruna apresentou a maior frequência de propriedades positivas (12,5\%) e de animais soropositivos
$(3,8 \%)$. Dentre as fêmeas e machos, $13(2,5 \%)$ e $2(0,81 \%)$ animais foram soropositivos, respectivamente, sem, contudo, haver diferença estatística $(\mathrm{p}=0,163)$.

$\mathrm{Na}$ análise univariada para os fatores de risco associados à ocorrência de propriedades positivas para leptospirose, as variáveis selecionadas ( $\mathrm{p} \leq 0,2)$ foram (Tabela 4): presença de gatos ( $p=0,112)$, ocorrência de abortamentos $(p=0,097)$ e compra de bovinos ( $p=0,184)$. No entanto, não foram identificados fatores de risco na análise múltipla.

Para brucelose, as variáveis selecionadas na análise univariada foram (Tabela 5): tipo de criação $(0,078)$, presença de equídeos $(\mathrm{p}=0,100)$, compra de bovinos $(\mathrm{p}=0,095)$ e assistência veterinária $(\mathrm{p}=0,181)$. $\mathrm{Na}$ análise de regressão logística (Tabela 6), comprar bovinos foi identificado como fator de risco (odds ratio = 5,25; IC95\% 1,05-26,35; $\mathrm{p}=0,044)$.

Tabela 1. Frequência de leptospirose bovina por propriedade de agricultura familiar e por animal no agreste paraibano, no período de julho a agosto de 2011.

\begin{tabular}{|c|c|c|c|c|c|c|}
\hline \multirow{2}{*}{ Município } & \multicolumn{3}{|c|}{ Propriedades } & \multicolumn{3}{|c|}{ Animais } \\
\hline & Total & Positivas & $\%$ & Total & Positivos & $\%$ \\
\hline Araruna & 32 & 07 & 21,8 & 183 & 09 & 4,9 \\
\hline Areial & 11 & 01 & 9,0 & 59 & 01 & 1,6 \\
\hline Belém & 43 & 06 & 13,9 & 297 & 08 & 2,6 \\
\hline Cacimba de Dentro & 35 & 09 & 25,7 & 211 & 09 & 4,2 \\
\hline Massaranduba & 09 & 01 & 11,1 & 21 & 01 & 4,7 \\
\hline Total & 130 & 24 & 18,4 & 771 & 28 & 3,6 \\
\hline
\end{tabular}

Tabela 2. Frequência de leptospirose bovina por propriedade de agricultura familiar e por animal no agreste paraibano, segundo o sorovar reagente, no período de julho a agosto de 2011.

\begin{tabular}{|c|c|c|c|c|}
\hline \multirow[b]{2}{*}{ Sorovar } & \multicolumn{2}{|c|}{ Propriedades } & \multicolumn{2}{|c|}{ Animais } \\
\hline & $\begin{array}{c}\text { Proporção de } \\
\text { propriedades positivas }\end{array}$ & Frequência (\%) & $\begin{array}{c}\text { Proporção de } \\
\text { animais soropositivos }\end{array}$ & Frequência (\%) \\
\hline Australis & $3 / 24$ & 12,5 & $3 / 28$ & 10,7 \\
\hline Copenhageni & $1 / 24$ & 4,1 & $1 / 28$ & 3,6 \\
\hline Pomona & $3 / 24$ & 12,5 & $3 / 28$ & 10,7 \\
\hline Hardjo & $7 / 24$ & 29,1 & $10 / 28$ & 35,7 \\
\hline Shermani & $2 / 24$ & 8,3 & $2 / 28$ & 7,1 \\
\hline Patoc & $6 / 24$ & 25 & $7 / 28$ & 25 \\
\hline Sentot & $2 / 24$ & 8,3 & $2 / 28$ & 7,1 \\
\hline
\end{tabular}

Tabela 3. Frequência de brucelose bovina por propriedade de agricultura familiar e por animal no agreste paraibano, no período de julho a agosto de 2011 .

\begin{tabular}{|c|c|c|c|c|c|c|}
\hline \multirow{2}{*}{ Município } & \multicolumn{3}{|c|}{ Propriedades } & \multicolumn{3}{|c|}{ Animais } \\
\hline & Total & Positivas & $\%$ & Total & Positivos & $\%$ \\
\hline Araruna & 32 & 04 & 12,5 & 183 & 07 & 3,8 \\
\hline Areial & 11 & 01 & 9,0 & 59 & 01 & 1,6 \\
\hline Belém & 43 & 04 & 9,3 & 297 & 06 & 2,0 \\
\hline Cacimba de Dentro & 35 & 01 & 2,8 & 211 & 01 & 0,4 \\
\hline Massaranduba & 09 & $\mathrm{OO}$ & 0 & 21 & $\mathrm{OO}$ & 0 \\
\hline Total & 130 & 10 & 7,7 & 771 & 15 & 1,94 \\
\hline
\end{tabular}


Tabela 4. Distribuição das variáveis analisadas como possíveis fatores de risco para leptospirose bovina em propriedades rurais de agricultura familiar no agreste paraibano, no período de julho a agosto de 2011

\begin{tabular}{|c|c|c|c|}
\hline Variáveis & 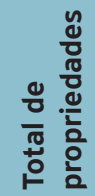 & 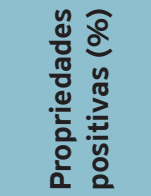 & $\frac{2}{\frac{2}{3}}$ \\
\hline \multicolumn{4}{|l|}{ Tipo de criação } \\
\hline Semiconfinado & 1 & $0(0,0)$ & \\
\hline Extensivo & 129 & $24(18,6)$ & 1,000 \\
\hline \multicolumn{4}{|l|}{ Tipo de exploração } \\
\hline Corte & 12 & $4(33,3)$ & \\
\hline Leite & 13 & $2(15,4)$ & \\
\hline Mista & 105 & $18(17,1)$ & 0,374 \\
\hline \multicolumn{4}{|c|}{ Raça de bovinos predominante } \\
\hline Zebu & 1 & $0(0,0)$ & \\
\hline Europeu de leite & 1 & $0(0,0)$ & \\
\hline Mestiço & 128 & $24(18,8)$ & 0,795 \\
\hline \multicolumn{4}{|l|}{ Tamanho do rebanho } \\
\hline Até 7 animais & 70 & $15(21,4)$ & \\
\hline$\geq 8$ animais & 60 & $9(15,0)$ & 0,475 \\
\hline \multicolumn{4}{|c|}{ Presença de caprino/ovino } \\
\hline Sim & 29 & $6(20,7)$ & \\
\hline Não & 101 & $18(17,8)$ & 0,937 \\
\hline \multicolumn{4}{|c|}{ Presença de equídeos } \\
\hline Sim & 65 & $14(21,5)$ & \\
\hline Não & 65 & $10(15,4)$ & 0,498 \\
\hline \multicolumn{4}{|l|}{ Presença de suínos } \\
\hline Sim & 35 & $7(20,0)$ & \\
\hline Não & 95 & $17(17,9)$ & 0,984 \\
\hline \multicolumn{4}{|l|}{ Presença de aves } \\
\hline Sim & 120 & $21(17,5)$ & \\
\hline Não & 10 & $3(30,0)$ & 0,392 \\
\hline \multicolumn{4}{|l|}{ Presença de cães } \\
\hline Sim & 117 & $22(18,8)$ & \\
\hline Não & 13 & $2(15,4)$ & 1,000 \\
\hline \multicolumn{4}{|l|}{ Presença de gatos } \\
\hline Sim & 100 & $15(15,0)$ & \\
\hline Não & 30 & $9(30,0)$ & $0,112^{*}$ \\
\hline \multicolumn{4}{|l|}{ Comprar bovinos } \\
\hline Sim & 83 & $12(14,5)$ & \\
\hline Não & 47 & $12(25,5)$ & $0,184^{*}$ \\
\hline \multicolumn{4}{|l|}{ Vender bovinos } \\
\hline Sim & 25 & $3(12,0)$ & \\
\hline Não & 105 & $21(20,0)$ & 0,566 \\
\hline \multicolumn{4}{|l|}{ Aluguel de pastos } \\
\hline Sim & 4 & $0(0,0)$ & \\
\hline Não & 126 & $24(19,0)$ & 1,000 \\
\hline \multicolumn{4}{|l|}{ Compartilhar pastos } \\
\hline Sim & 3 & $0(0,0)$ & \\
\hline Não & 127 & $24(18,9)$ & 1,000 \\
\hline \multicolumn{4}{|c|}{ Presença de áreas alagadiças } \\
\hline Sim & 11 & $1(9,1)$ & \\
\hline Não & 119 & $23(19,3)$ & 0,688 \\
\hline \multicolumn{4}{|c|}{ Presença de roedores } \\
\hline Sim & 41 & $8(19,5)$ & \\
\hline Não & 89 & $16(18,0)$ & 1,000 \\
\hline \multicolumn{4}{|c|}{ Realizar controle de roedores } \\
\hline Sim & 47 & $6(12,8)$ & \\
\hline Não & 83 & $18(21,7)$ & 0,208 \\
\hline Possuir piquetes de & & & \\
\hline Sim & 18 & $2(11,1)$ & \\
\hline Não & 112 & $22(19,6)$ & 0,524 \\
\hline Assistência veteriná & & & \\
\hline Sim & 22 & $2(9,1)$ & \\
\hline Não & 108 & $22(20,4)$ & 0,364 \\
\hline
\end{tabular}

*Variáveis selecionadas para análise múltipla $(p \leq 0,2)$.
Tabela 5. Distribuição das variáveis analisadas como possíveis fatores de risco para brucelose bovina em propriedades rurais de agricultura familiar no agreste paraibano, no período de julho a agosto de 2011 .

\begin{tabular}{|c|c|c|c|}
\hline Variáveis & 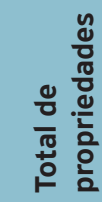 & 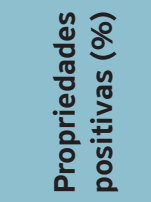 & $\frac{2}{\frac{2}{10}}$ \\
\hline \multicolumn{4}{|l|}{ Tipo de criação } \\
\hline Semiconfinado & 1 & $1(100,0)$ & \\
\hline Extensivo & 128 & $9(7,0)$ & $0,078^{*}$ \\
\hline \multicolumn{4}{|l|}{ Tipo de exploração } \\
\hline Corte & 12 & $0(0,0)$ & \\
\hline Leite & 13 & $1(7,7)$ & \\
\hline Mista & 105 & $9(8,6)$ & 0,573 \\
\hline \multicolumn{4}{|c|}{ Raça de bovinos predominante } \\
\hline Zebu & 1 & $0(0,0)$ & \\
\hline Europeu de leite & 1 & $0(0,0)$ & \\
\hline Mestiço & 128 & $10(7,8)$ & 0,918 \\
\hline \multicolumn{4}{|c|}{ Tamanho do rebanho } \\
\hline Até 7 animais & 70 & $5(7,1)$ & \\
\hline$\geq 8$ animais & 60 & $5(8,3)$ & 1,000 \\
\hline \multicolumn{4}{|c|}{ Presença de caprino/ovino } \\
\hline Sim & 29 & $4(13,8)$ & \\
\hline Não & 101 & $6(5,9)$ & 0,229 \\
\hline \multicolumn{4}{|c|}{ Presença de equídeos } \\
\hline Sim & 65 & $8(12,3)$ & \\
\hline Não & 65 & $2(3,1)$ & $0,100^{*}$ \\
\hline \multicolumn{4}{|l|}{ Presença de suínos } \\
\hline Sim & 35 & $3(8,6)$ & \\
\hline Não & 95 & $7(7,4)$ & 1,000 \\
\hline \multicolumn{4}{|l|}{ Presença de cães } \\
\hline Sim & 117 & $9(7,7)$ & \\
\hline Não & 13 & $1(7,7)$ & 1,000 \\
\hline \multicolumn{4}{|l|}{ Comprar bovinos } \\
\hline Sim & 55 & $7(12,7)$ & \\
\hline Não & 75 & $3(4,0)$ & $0,095^{*}$ \\
\hline \multicolumn{4}{|l|}{ Vender bovinos } \\
\hline Sim & 16 & $3(18,8)$ & \\
\hline Não & 114 & $7(6,1)$ & $0,107^{*}$ \\
\hline \multicolumn{4}{|c|}{$\begin{array}{l}\text { Utilização de vacina contra } \\
\text { brucelose }\end{array}$} \\
\hline Sim & 37 & $2(5,4)$ & \\
\hline Não & 93 & $7(7,5)$ & 1,000 \\
\hline \multicolumn{4}{|l|}{ Aluguel de pastos } \\
\hline Sim & 4 & $0(0,0)$ & \\
\hline Não & 126 & $10(7,9)$ & 1,000 \\
\hline \multicolumn{4}{|l|}{ Compartilhar pastos } \\
\hline Sim & 3 & $0(0,0)$ & \\
\hline Não & 127 & $10(7,9)$ & 1,000 \\
\hline \multicolumn{4}{|c|}{ Presença de áreas alagadiças } \\
\hline Sim & 11 & $0(0,0)$ & \\
\hline Não & 119 & $10(8,4)$ & 1,000 \\
\hline \multicolumn{4}{|c|}{ Possuir piquetes de parição } \\
\hline Sim & 18 & $1(5,6)$ & \\
\hline Não & 107 & $9(8,4)$ & 1,000 \\
\hline \multicolumn{4}{|c|}{ Assistência veterinária } \\
\hline Sim & 22 & $3(13,6)$ & \\
\hline Não & 108 & $6(5,6)$ & 0,181 * \\
\hline
\end{tabular}

*Variáveis selecionadas para análise múltipla $(p \leq 0,2)$. 
Tabela 6. Fator de risco para brucelose bovina em propriedades rurais de agricultura familiar no agreste paraibano, no período de julho a agosto de 2011.

\begin{tabular}{|lccc|}
\hline Fator de risco & $\begin{array}{c}\text { Odds } \\
\text { ratio }\end{array}$ & IC95\% & Valor p \\
\hline Comprar bovinos & 5,25 & $1,05-26,35$ & 0,044 \\
\hline
\end{tabular}

\section{DISCUSSÃO}

A aplicação da SAM para a detecçáo de anticorpos anti-Leptospira spp. em 771 bovinos provenientes de 130 propriedades rurais de agricultura familiar no agreste paraibano permitiu a visualização da abrangência e da disseminação da infecção por leptospiras na região e, principalmente, os sorovares prevalentes. Foi observado que em 18,4\% das propriedades e em 3,6\% dos animais foram detectados anticorpos anti-Leptospira spp. CASTRo et al. (2008) examinaram, pela SAM, 8.216 fêmeas bovinas procedentes de 1.021 propriedades do estado de São Paulo e verificaram que as prevalências de propriedades positivas e de animais soropositivos foram de 71,3 e 49,4\%, respectivamente. Oliveira et al. (2009), no estado da Bahia, também utilizaram fêmeas bovinas e a SAM como teste de diagnóstico, e verificaram que 1.414 propriedades $1.076(77,93 \%)$ foram positivas, e 10.823 animais $4.253(45,42 \%)$ foram soropositivos. No presente trabalho, as frequências de propriedades positivas e de animais soropositivos foram muito inferiores às encontradas nesses estudos. As vacinas antileptospirose disponíveis no mercado são bacterinas inativadas, baseadas na proteção dirigida ao antígeno LPS das leptospiras, ressaltando-se sua interferência na SAM por cerca de seis meses após a vacinação (Freudenstein; Hein, 1991; NArdi Júnior et al., 2007), o que poderia em algum momento deste estudo ter sido considerada como resposta sorológica positiva. Sabe-se que a vacinação contra a leptospirose bovina no Estado de Paraíba não é uma prática disseminada. Isso pode justificar a baixa frequência de positividade encontrada no presente trabalho, uma vez que as reaçóes sorológicas provenientes de anticorpos vacinais podem influenciar a frequência de animais soropositivos (CASTro et al., 2008). Apesar disso, sugere-se a necessidade de adoção e/ou intensificação de medidas de prevenção e controle, com o objetivo de evitar perdas econômicas e transmissão do agente aos seres humanos.

O sorovar Hardjo foi o mais frequente no presente estudo, tanto nas propriedades $(29,1 \%)$ quanto nos animais (35,7\%). Similarmente, nos Estados da Bahia e São Paulo, esse sorovar foi apontado como o mais prevalente nas propriedades e nos animais (CAstro et al., 2008; Oliveira et al., 2009), confirmando os achados clássicos em bovinos. Este sorovar, também relatado como prevalente em rebanhos bovinos de outros países, tem sido reconhecido como significante causa de falhas e alteraçóes nos parâmetros reprodutivos (Higgins et al., 1980; SLEE et al. 1983; Tebrugge; Dreyer, 1985; Prescott et al., 1988; Ellis, 1994; Faine et al., 1999; Guitian et al. 1999; Chiareli et al., 2012).

Além do sorovar Hardjo, que geralmente é transmitido entre bovinos, foi observada a ocorrência de reaçóes para os sorovares Australis, Copenhageni, Pomona, Shermani, Patoc e Sentot. Esses sorovares são considerados acidentais para bovinos, e a transmissão indireta está associada ao contato com o meio ambiente contaminado por leptospiras oriundas de espécies silvestres ou de outras espécies domésticas (CASTRO et al., 2008).

Apesar de não terem sido identificados fatores de risco para leptospirose, algumas variáveis merecem destaque em função da frequência de propriedades positivas. Propriedades com manejo extensivo, exploração de corte e que não realizam controle de roedores apresentaram frequências de positividade maiores em relação às outras categorias (18,6, 33,3 e 21,7\%, respectivamente). De fato, em propriedades com manejo extensivo, a chance de infecção aumenta, uma vez que as possibilidades de os animais entrarem em contato com materiais contaminados com leptospiras, como pastos, água e materiais de parto e abortamento, são maiores. Da mesma forma, em propriedades com exploração tipo corte, geralmente os rebanhos são grandes e mantidos pela compra de animais de outras propriedades, sem, contudo, a realização de diagnóstico de leptospirose. A não realização do controle de roedores é um fator de risco clássico para leptospirose, pois esses animais são os principais reservatórios da bactéria (FAINe et al., 1999).

Dados oficiais da brucelose bovina obtidos em inquéritos sorológicos em vários Estados brasileiros indicaram prevalência de propriedades positivas e de animais soropositivos, variando de $0,32-41,5 \%$ e $0,06-10,2 \%$, respectivamente (Alves et al., 2009; Azevedo et al., 2009; ChATE et al., 2009; Dias et al., 2009a; Dias et al., 2009b; GonÇALVEs et al., 2009a; Gonçalves et al., 2009b; Klein-Gunnewiek et al., 2009; Marvulo et al., 2009; Negreiros et al., 2009; Ogata et al., 2009; Rocha et al., 2009; Sikusawa et al., 2009; Silva et al., 2009; Villar et al., 2009). No presente trabalho, $7,7 \%$ das propriedades foram positivas e 1,9\% dos animais foram soropositivos, o que se encontra dentro da variação das prevalências obtidas em outros Estados.

$\mathrm{O}$ combate à brucelose bovina pode ser dividido em quatro fases distintas (Paulin; Ferreira Neto, 2003):

(a) rebaixamento da prevalência para valores inferiores a $2 \%$, sendo necessária, para isso, uma cobertura vacinal de $80 \%$ com a vacina B19;

(b) abandono da vacinação e adoção das medidas de diagnóstico e sacrifício sistemáticos dos animais soropositivos;

(c) solução de problemas residuais; e (d) adoção de ações de vigilância para que o retorno da infecção seja impedido, ou caso reapareça, seja rapidamente detectado e eliminado. 
Com base no estudo epidemiológico realizado no Estado de Santa Catarina, no qual a prevalência de focos foi de $0,32 \%$ e a prevalência de animais soropositivos foi de $0,06 \%$ (SiKusawa et al., 2009), o MAPA publicou uma portaria em 2004 excluindo a obrigatoriedade de vacinação contra a brucelose bovina nesse estado (BrasIL, 2004).

No presente trabalho, não foi realizado um planejamento amostral para a regiáo, bem como não foram estabelecidos critérios de seleção de propriedades e animais, o que pode influenciar na determinação das frequências de propriedades positivas e animais soropositivos, de modo que se torna incoerente sugerir alguma estratégia de ação. De qualquer maneira, considerando as elevadas frequências de focos e de animais soropositivos, sugere-se que esforços sejam concentrados na intensificação da vacinação de bezerras, com o intuito de que seja alcançada uma prevalência compatível com as açôes de teste e sacrifício de animais.

O município de Araruna apresentou a maior frequência de propriedades positivas e de animais soropositivos, o que pode ser justificado pelo fato de tal município estar localizado na divisa da Paraíba com o Rio Grande do Norte, situação que pode dificultar a fiscalização do trânsito de animais na regiáo, principalmente pela existência de estradas clandestinas, contribuindo para a introdução de animais infectados.

A variável comprar bovinos foi apontada como fator de risco para a brucelose bovina. A compra de animais infectados é amplamente relatada como o principal fator de introdução de brucelose em rebanhos livres. Dos 15 Estados nos quais foram conduzidos estudos epidemiológicos como parte do Programa Nacional de Controle e Erradicação da
Brucelose e Tuberculose Bovina (PNCEBT), em seis deles (Bahia, Goiás, Minas Gerais, Paraná, Rio de Janeiro e São Paulo) essa variável foi apontada como fator de risco (Alves et al., 2009; Dias et al., 2009a; Dias et al., 2009b; Gonçalves et al., 2009a; KLein-GunNewiek et al., 2009; Rocha et al., 2009). Dentro dessa variável, alguns fatores podem atuar de forma independente ou em associação, como: frequência de compra, origem dos animais e histórico de realização de testes sorológicos para brucelose (CRAWFORD et al. 1990; Alves et al., 2009). O verdadeiro problema não é a introdução de animais, prática rotineira nos rebanhos bovinos, mas sim a aquisiçấo de animais sem cuidados sanitários, ou seja, sem a realização de testes ou o conhecimento da condição sanitária do rebanho de origem (Alves et al., 2009).

\section{CONCLUSÃO}

Constatou-se que, para leptospirose, $18,4 \%$ das propriedades tiveram animais reagentes e 3,6\% dos animais foram soropositivos, bem como o sorovar Hardjo foi o mais frequente; para brucelose, $7,7 \%$ das propriedades foram positivas e $1,9 \%$ dos animais foram soropositivos, o que sugere a necessidade de intensificação e/ou adoção de medidas de prevenção e controle com o objetivo de evitar perdas econômicas e transmissão dos agentes aos seres humanos. Também sugere-se que a compra de animais seja precedida do conhecimento da sua condição sanitária.

\section{REFERÊNCIAS}

ACHA, P.N.; SZYFRES, B. Zoonosis y enfermedades transmisibles comunes al hombre y a los animales: bacterioses e micoses. 3 ed. Washington: OPAS, $2001.416 \mathrm{p}$.

ALVES, A.J.S.; GONÇALVES, V.S.P.; FIGUEIREDO, V.C.F.; LÔBO, J.R.; BAHIENSE, L.; AMAKU, M.; FERREIRA, F.; FERREIRA NETO, J.S.; DIAS, R.A. Situação epidemiológica da brucelose bovina no Estado da Bahia. Arquivo Brasileiro de Medicina Veterinária e Zootecnia, v.61, p.6-13, 2009.

AZEVEDO, S.S.; FERREIRA NETO, J.S.; DIAS, R.A.; FERREIRA, F.; AMAKU, M.; FIGUEIREDO, V.C.F.; LÔBO, J.R.; GONÇALVES, V.S.P.; SOUZA, A.C.; VASCONCELLOS, S.A. Situação epidemiológica da brucelose bovina no Estado do Espírito Santo. Arquivo Brasileiro de Medicina Veterinária e Zootecnia, v.61, p.19-26, 2009.

BRASIL. Manual Técnico do Programa Nacional de Controle e Erradicação da Brucelose e Tuberculose (PNCEBT). Departamento de Defesa Animal, Secretaria de Defesa Agropecuária, Ministério da Agricultura, Pecuária e Abastecimento (MAPA), Brasília. 2006
BRASIL. Excluir o Estado de Santa Catarina da obrigatoriedade de vacinação das fêmeas bovinas $e$ bubalinas contra a brucelose. Departamento de Defesa Animal, Secretaria de Defesa Agropecuária, MAPA. Diário Oficial da República Federativa do Brasil, Brasília, 29 jan.2004, Seção 1, 2, 3, 2004.

CASTRO, V.; AZEVEDO, S.S.; GOTTI, T.B.; BATISTA, C.S.A.; GENTILI, J.; MORAES, Z. M.; SOUZA, G.O.; VASCONCELLOS, S.A.; GENOVEZ, M.E. Soroprevalência da leptospirose em fêmeas bovinas em idade reprodutiva no Estado de São Paulo, Brasil. Arquivos do Instituto Biológico, São Paulo, v.75, n. 1, p.3$11,2008$.

CHATE, S.C.; DIAS, R.A.; AMAKU, M.; FERREIRA, F.; MORAES, G.M.; COSTA NETO, A.A.; MONTEIRO, L.A.R.C.; LÔBO, J.R.; FIGUEIREDO, V.C.F.; GONÇALVES, V.S.P.; FERREIRA NETO, J.S. Situação epidemiológica da brucelose bovina no Estado do Mato Grosso do Sul. Arquivo Brasileiro de Medicina Veterinária e Zootecnia, v.61, p.46-55, 2009. 
CHIARELI, D.; COSATE, M.R.V.; MOREIRA, E.C.; LEITE, R.C.; LOBATO, F.C.F.; SILVA, J.A.; TEIXEIRA, J.F.B.; MARCELINO, A.P. Controle da leptospirose em bovinos de leite com vacina autógena em Santo Antônio do Monte, Minas Gerais. Pesquisa Veterinária Brasileira, v.32, n.7, p.633-639, 2012.

COLE, J.R.; SULZER, C.R.; PULSSELY, P.R. Improved microtechnique for the leptospiral microscopic agglutination. Applied Microbiology, v.5, n.6, p.976-980, 1973.

CRAWFORD, R.P.; HUBER, J.D.; ADAMS, B.S. Epidemiology and surveillance. In: NIELSEN, K; DUNCAN J.R. (Org). Animal brucellosis. Boca Raton: CRC Press, 1990. p.317-361.

DIAS, J.A.; MÜLLER, E.E.; DIAS, R.A.; FREITAS, J.C.; AMAKU, M.; FERREIRA, F.; SILVA, M.C.P.; LÔBO, J.R.; FIGUEIREDO, V.C.F.; GONÇALVES, V.S.P.; FERREIRA NETO, J.S. Situação epidemiológica da brucelose bovina no Estado do Paraná. Arquivo Brasileiro de Medicina Veterinária e Zootecnia, v.61, p.66-76, 2009a.

DIAS, R.A.; GONÇALVES, V.S.P.; FIGUEIREDO, V.C.F.; LÔBO, J.R.; LIMA, Z.M.B.; PAULIN, L.M.S.; GUNNEWIEK, M.F.K.; AMAKU, M.; FERREIRA NETO, J.S.; FERREIRA, F. Situação epidemiológica da brucelose bovina no Estado de São Paulo. Arquivo Brasileiro de Medicina Veterinária e Zootecnia, v.61, p.118-125, 2009b.

ELLIS, W.A. Leptospirosis as a cause of reproductive failure. Veterinary Clinics of North America: Food Animal Practice. v.10, p.463-478, 1994.

EMBRAPA GADO DE LEITE. Produção de leite no Sudeste do Brasil. Disponível em: <http://sistemasdeproducao.cnptia. embrapa.br/FontesHTML/Leite/LeiteSudeste/index.html>. Acesso em: 19 mar. 2012.

FAINE, S.; ADLER, B.; BOLIN, C.; PEROLAT, P. Leptospira and leptospirosis. 2nd ed. Melbourne: MediSci, 1999. 272 p.

FREUDENSTEIN, H.; HEIN, B. Potency of leptospiral vaccines and protection against chronic infection in golden hamsters. Comparative Immunology, Microbiology \& Infectious Diseases, v.14, n.3, p.229-234, 1991.

GALTON, M.M.; SULZER, C.R.; SANTA ROSA, C.A.; FIELDS, M.J. Application of a microtechnique to the agglutination test for leptospiral antibodies. Archive of Applied Microbiology, v.13, p.81-85, 1965.

GONÇALVES, V.S.P.; DELPHINO, M.K.V.C.; DIAS, R.A.; FERREIRA, F.; AMAKU, M.; FERREIRA NETO, J.S.; PORTO, T.B.; ALVES, C.M.; FIGUEIREDO, V.C.F.; LÔBO, J.R. Situação epidemiológica da brucelose bovina no Estado de Minas Gerais. Arquivo Brasileiro de Medicina Veterinária e Zootecnia, v.61, p.35-45, 2009a.

GONÇALVES, V.S.P.; RIBEIRO, L.A.; CALDAS, R.A.; FRANCISCO, P.F.C.; DIAS, R.A.; FERREIRA, F.; AMAKU, M.; FERREIRA NETO, J.S.; FIGUEIREDO, V.C.F.; LÔBO, J.R.; BORGES, J.R.J. Situação epidemiológica da brucelose bovina no Distrito Federal. Arquivo Brasileiro de Medicina Veterinária e Zootecnia, v.61, p.14-18, 2009b.
GUITIAN, J.; TRUMOND, M.C.; HIETALA, S.K. Infertility and abortion among first-lactation dairy cows seropositive or seronegative for Leptospira interrogans serovar Hardjo. Journal of the American Veterinary Medical Association, v.215, p.515-518, 1999.

HIGGINS, R.J.; HARBOURNE, J.F.; LITTLE, T.W.A.; STEVENS, A.E. Mastitis and abortion in dairy cattle associated with leptospira of the serotype Hardjo. Veterinary Record, v.107, p.307-310, 1980.

HOSMER, D.W.; LEMESHOW, S. Applied logistic regression.New York: John Wiley \& Sons, 2000. 375 p.

IBGE. Censo Agropecuário de 2006, Instituto Brasileiro de Geografia e Estatística. Disponível em: <http://www.ibge. com.br/estadosat/temas.php?sigla=pb\&tema=censoagro $>$. Acesso em: 10 jan.2012.

KLEIN-GUNNEWIEK, M.F.C.; AMAKU, M.; DIAS, R.A.; FERREIRA, F.; GITTI, C.B.; PEREIRA, L.A.; FIGUEIREDO, V.C.F.; LOBO, J.R.; GONÇALVES, V.S.P.; FERREIRA NETO, J.S. Situação epidemiológica da brucelose bovina no Estado do Rio de Janeiro. Arquivo Brasileiro de Medicina Veterinária e Zootecnia, v.61, p.77-84, 2009.

MARVULO, M.F.V.; FERREIRA, F.; DIAS, R.A.; AMAKU, M.; GROFF, A.C.M.; GONÇALVES, V.S.P.; FIGUEIREDO, V.C.F.; LÔBO, J.R.; FERREIRA NETO, J.S. Situação epidemiológica da brucelose bovina no Estado do Rio Grande do Sul. Arquivo Brasileiro de Medicina Veterinária e Zootecnia, v.61, p.93-102, 2009.

NARDI JÚNIOR, G.; GENOVEZ, M.E.; RIBEIRO, M.G.; CASTRO, V.; JORGE, A.M. Interference of vaccinal antibodies on serological diagnosis of leptospirosis in vaccinated buffalo using two types of commercial vaccines. Brazilian Journal of Microbiology, v.38, p.363-368, 2007.

NEGREIROS, R.L.; DIAS, R.A.; FERREIRA, F.; FERREIRA NETO, J.S.; GONÇALVES, V.S.P.; SILVA, M.C.P.; FIGUEIREDO, V.C.F.; LÔBO, J.R.; FREITAS, J.; AMAKU, M. Situação epidemiológica da brucelose bovina no Estado de Mato Grosso. Arquivo Brasileiro de Medicina Veterinária e Zootecnia, v.61, p.56-65, 2009.

OGATA, R.A.; GONÇALVES, V.S.P.; FIGUEIREDO, V.C.F.; LÔBO, J.R.; RODRIGUES, A.L.; AMAKU, M.; FERREIRA, F.; FERREIRA NETO, J.S.; DIAS, R.A. Situação epidemiológica da brucelose bovina no Estado do Tocantins. Arquivo Brasileiro de Medicina Veterinária e Zootecnia, v.61, p.126-134, 2009.

OIE. World Organization for Animal Health. Terrestrial animal health code. Bovine Brucellosis. Disponível em: <http://www. oie.int/index.php? id=169\&L=0\&htmfile=chapitre_1.11.3.h tm>. Acesso em: 19 mar. 2012.

OLIVEIRA, F.C.S; AZEVEDO, S.S.; PINHEIRO, S.R.; VIEGAS, S.A.R.A.; BATISTA, C.S.A.; COELHO, C.P.; MORAES, Z.M.; SOUZA, G.O.; GONÇALES, A.P.; ALMEIDA, C.A.S.; VASCONCELLOS, S.A. Soroprevalência de leptospirose em fêmeas bovinas em idade reprodutiva no Estado da Bahia. Arquivos do Instituto Biológico, São Paulo, v.76, p.539-546, 2009. 
PAULIN, L.M.; FERREIRA NETO, J.S. O combate à brucelose bovina: situação brasileira. Jaboticabal: Funep, 2003. 154p.

PRESCOTT, J.F.; MILLER, R.B.; NICHOLSON, V.M.; MARTIN, S.W.; LESNICK ,T. Seroprevalence and association with abortion of leptospirosis in cattle in Ontário. Archive of Canadian Journal of Veterinary Research, v.52, p.210-215, 1988.

ROCHA, W.V.; GONÇALVES, V.S.P.; COELHO, C.G.N.F.L.; BRITO, W.M.E.D.; DIAS, R.A.; DELPHINO, M.K.V.C.; FERREIRA, F.; AMAKU, M.; FERREIRA NETO, J.S.; FIGUEIREDO, V.C.F.; LÔBO, J.R.; BRITO, L.A.B. Situação epidemiológica da brucelose bovina no Estado de Goiás. Arquivo Brasileiro de Medicina Veterinária e Zootecnia, v.61, p.27-34, 2009.

SIKUSAWA, S.; AMAKU, M.; DIAS, R.A.; FERREIRA NETO, J.S.; MARTINS, C.; GONÇALVES, V.S.P.; FIGUEIREDO, V.C.F.; LÔBO, J.R.; FERREIRA, F. Situação epidemiológica da brucelose bovina no Estado de Santa Catarina. Arquivo Brasileiro de Medicina Veterinária e Zootecnia, v.61, p.103$108,2009$.
SILVA, V.G.S.O.; DIAS, R.A.; FERREIRA, F.; AMAKU, M.; COSTA, E.L.S.; LÔBO, J.R.; FIGUEIREDO, V.C.F.; GONÇALVES, V.S.P.; FERREIRA NETO, J.S. Situação epidemiológica da brucelose bovina no Estado de Sergipe. Arquivo Brasileiro de Medicina Veterinária e Zootecnia, v.61, p.109-117, 2009.

SLEE, K.J.; MCORIST, S.; SKILLBECK, N.W. Bovine abortion associated with Leptospira interrogans serovar Hardjo infection. Australian Veterinary Journal, v.60, p.204-206, 1983.

TEBRUGGE, L.; DREYER, T. Leptospira interrogans serovar hardjo associated with bovine abortion in South Africa. Onderstepoort Journal of Veterinary Research, v.52, p.51-52, 1985.

VILLAR, K.S.; AMAKU, M.; DIAS, R.A.; FERREIRA NETO, J.S.; BENITEZ, F.; GONÇALVES, V.S.P.; FIGUEIREDO, V.C.F.; LÔBO, J.R.; FERREIRA, F. Situação epidemiológica da brucelose bovina no Estado de Rondônia. Arquivo Brasileiro de Medicina Veterinária e Zootecnia, v.61, p.85-92, 2009.

ZAR, J.H. Biostatistical Analysis. 4th ed. Upper Saddle River: Prentice Hall, 1999. 663p. 